\title{
Analyzing Some of the Dual-Core Yarn Spinning Parameters on Yarn and Various Fabric Properties
}

\author{
Sevim Hümeyra Çelikkan Aydoğdu, Demet Yılmaz \\ Suleyman Demirel University, Engineering Faculty, Textile Engineering Department, West Campus, Isparta, Turkey
}

Corresponding Author: Demet Y1lmaz, demetyilmaz@sdu.edu.tr.

\begin{abstract}
Nowadays, in order to improve some of the properties of core-spun yarns, a new type of core-spun yarn called as dual-core has been developed. In literature, there are limited studies and hence findings about dual-core yarns. Therefore, in this study, dual-core yarns were produced with three different sheath fibres (viscose, cotton and cotton/Tencel blended fibres) and two different core filament linear density (50 and 70 denier) having three different yarn counts (12/1 Ne, 16/1 Ne and 20/1 Ne). Woven and knitted fabrics were manufactured and yarn quality parameters and some of the fabric properties such as fabric pilling behaviour, breaking and bursting strength, breaking elongation and bending rigidity were investigated. Therefore, at the end of study, it was possible to investigate the effect of sheath fibre type, yarn count and core filament linear density on yarn and fabric properties of dual-
\end{abstract}

ARTICLE HISTORY

Received: 22.10.2018

Accepted: 13.02.2019

\section{KEYWORDS}

Dual-core yarn, core-spun yarn, elastic fabrics, Spandex

\section{INTRODUCTION}

In recent years, usage of elastic materials and demands to elastic fabrics and garments have been increased due to their stretch and recovery capability and thus wear comfort and fitness compared to common textile products [1]. Elastic materials under different names such as Lycra, Spandex, T400, PBT etc. are widely used in casual apparel products, denim fabrics, sportswear, medical textiles etc. to provide the stretchability and elasticity. One commonly used method to produce elastic woven or knitted fabrics is core-spun yarn spinning technology. In core-spun yarn spinning method, any type of elastic filament specially placed to centre of the yarn is covered and wrapped by short staple fibres such as cotton, wool or man-made fibres. Produced yarn is called as core-spun and consisting of core filament and sheath parts. Core-spun yarn production method makes possible to optimally benefit the features of two different components in the same structure. In order to improve the properties of core-spun yarns, particularly recovery, stability and dimensional change, a new type of core-spun yarn called as dual-core yarn has been developed.
Core filaments such as soft (Elastane) and hard material (PES, PA etc.) are coated with staple natural or synthetic filaments and hence resultant yarn is composed of dual core filaments such as PET+Elastane or PA+Elastane, and sheath fibres. In particular, elastic-soft and semi elastichard core filaments are used in dual-core yarn production to enhance high elasticity obtained by elastic component and high recovering, stability and low shrinkage obtained by semi elastic component to dual-core yarns.

Core-spun yarns have been used for many years and therefore the effects of the elastic core, the sheath fibres for covering the yarn and various spinning parameters on structures and properties of core-spun yarns were investigated in many studies. However, textile producers and researchers have newly focused on dual-core spun yarns and hence there are a few works about the dual-core spun yarns [1-4]. Hua et al. [1] worked on the development of elastic core-spun yarn containing a mix of Spandex and polyethylene terephthalate/polytrimethylene terephthalate (PET/PTT) bi-component filament as a core material to obtain better elastic property. Spandex and PET/PTT bi-

To cite this article: Çelikkan Aydoğdu SH, Yılmaz D. 2019. Analyzing some of the dual-core yarn spinning parameters on yarn and various fabric properties Tekstil ve Konfeksiyon 29(3), 197-207. 
component filaments were covered with cotton fibres on a modified ring-spinning machine with a core spinning attachment. The experimental results indicated that dualcore yarns have much lower yarn stress decay as well as lower hairiness, $\mathrm{CVm}$ and higher elongation values compared to the core-spun yarns using only Spandex core filament. In addition, it was found that Spandex count significantly affects the breaking elongation and stress decay of dual-core yarns and elongation of the yarns increases with the increase of the draw ratio of Spandex. Kılıç [2] and Tantawy et al. [3], in their studies, fed dualcore filaments in two different ways to the yarn centre. Kılıç [2] welded PET and Spandex filaments by intermingling process and positioned the combined filaments in front roller nip in terms of a standard $\mathrm{V}$ grooved guide roller under certain tension (3.5). In second part of the study, PET and Spandex filaments were fed separately by similar guide roller under certain tension (for 3.5 for PET, 1.08 for Spandex). Intermingled and separately fed PET and Spandex core filaments were covered by cotton fibres and multicomponent dual-core yarns were obtained. Kılıç [2] determined that production methods (core-spun and dual-core) have statistically significant influence on yarn properties. In addition, it was indicated that production parameters such as twist, Elastane pre-draft also statistically affect the elasticity and growth values of woven fabrics. Tantawy et al. [3] studied the effect dualcore weft yarns with different yarn counts on the pilling properties of denim fabric (3/1 Z twill) and found that dualcore yarn type and yarn count have influence on fabric pilling property. Ertaş et al. [4] produced 16/1 Ne dual-core yarns for the weft thread using 77 dtex PES and 78 dtex Spandex core filaments and cotton wrapping fibres. In their study, it was determined that the construction has a much more impact on the fabric width and thus on the unit weight properties than the elasticity ratio. As the density increases, the elasticity value, permanent elongation and depth of the colour have been found out to decrease substantially due to more rigidity of the fabric resulted from higher fabric density. It was determined that the ratio between the elasticity and the permanent elongation values is not affected from the density changes, and remains at the same value in almost all the fabrics. In addition, permanent elongation value is superior at the same elasticity value compared to the conventional Elastane core wefts. As reported above, there are a few studies and findings about the dual-core yarns to understand the structure and features of this yarn type. In this study, we are interested in the identification of the effect of various process parameters on dual-core yarn and some of the fabric properties. Dual-core yarns having three different yarn counts were produced with three different sheath fibres and two different core filament linear densities. This study provides a better understanding the effect of sheath fibres, core filament and yarn finenesses on dual-core yarns. In addition, majority of the studies reported in the literature has focused on the usage of cotton fibre as a sheath fibre for core-spun yarns composed of single [5-24] and dual core filaments [1-4]. Present study was therefore undertaken to investigate the effect of different sheath fibre types on dual-core yarns.

\section{MATERIAL AND METHOD}

\subsection{Material}

In the study, it was produced dual-core spun yarns having $12 / 1 \mathrm{Ne}, 16 / 1 \mathrm{Ne}$ and 20/1 Ne yarn counts on Merlin conventional ring spinning machine. Cotton (100\%), viscose $(100 \%)$ and cotton/Tencel fibre blend (50/50\%) were used as a sheath part of the dual-core spun yarns. Fibre properties were given in Table 1. As a core material, X55 and Spandex filaments were used together for dualcore spun yarns. Linear densities of core filaments were 50 and 70 denier for X55, and 70 denier for Spandex. Spandex fibre, one of the most important thermo-plastic elastomeric fibres being commercially produced worldwide, is made with long chain synthetic polymers comprised of mostly segmented polyurethanes [25]. X55 is a Spandex fibre commercialized by Xanadu firm to provide crimp and stretch properties to material.

Similar to core-spun yarn, during the dual-core spun yarn production, X55 and Spandex (X55+Spandex) core filaments were supplied separately under control of a positive feed roller system and sent to the $\mathrm{V}$-grooved guide roller. And both core materials composed of X55+Spandex filaments were wrapped by cotton, viscose and cotton/Tencel covering fibres. During dual-core yarn production, core filaments were given to the drafting system under specific tension (draft), and the values were 1.1 for first type of core filament (X55) and 3.63 for second type of core filament (Spandex). Production parameters for dual-core yarns were that roving count was about 0.81-0.87 $\mathrm{Ne}$, ae was 4.0, spindle speed was 10500-11000 rpm [26].

Table 1. Fibre properties

\begin{tabular}{llll}
\hline Properties & Cotton & Viscose & Tencel \\
\hline Fibre length & $28.62 \mathrm{~mm}$ & $38 \mathrm{~mm}$ & $38 \mathrm{~mm}$ \\
Fineness & Mic 4.22 & $1.3 \mathrm{dtex}$ & $1.3 \mathrm{dtex}$ \\
Maturity & $97.2 \%$ & - & - \\
Tenacity & $30.58 \mathrm{~g} / \mathrm{tex}$ & - & - \\
Colour grade & $33-44$ & - & - \\
\hline
\end{tabular}




\subsection{Method}

Dual-core spun yarn samples were conditioned under standard atmospheric conditions of $20 \pm 1^{\circ} \mathrm{C}$ and $65 \pm 2 \%$ R.H. for $24 \mathrm{~h}$. Seven cops were tested for each yarn properties and one test was done on each cops. Yarn evenness and imperfections was tested on Uster Tester 5 at $400 \mathrm{~m} / \mathrm{min}$ test speed. Mechanical properties of the yarns were measured on Uster Tensorapid 4. To analyse the fabric properties, yarn samples were used as a weft yarn and woven fabrics were produced having plain weave and $30 \mathrm{~cm}^{*} 150 \mathrm{~cm}$ dimensions. Fabric density values were 39 warp/cm*18 weft/cm for $12 / 1 \mathrm{Ne}, 33 \mathrm{warp} / \mathrm{cm}^{*} 19 \mathrm{weft} / \mathrm{cm}$ for $16 / 1 \mathrm{Ne}$, and $33 \mathrm{warp} / \mathrm{cm}^{*} 21 \mathrm{weft} / \mathrm{cm}$ for $20 / 1 \mathrm{Ne}$ yarn counts. Pilling behaviour of all fabrics was tested on the Nu-Martindale Abrasion Tester according to TS EN ISO 12945-2 test method. Fabric strength and breaking elongation was tested according to TS EN ISO 139341/1999 on Lloyd LR5K Plus electronic tensile strength machine. Due to limited fabric sample, tensile properties of woven fabrics were tested for only weft direction. In the study, it was also obtained knitted samples from the dualcore spun yarns and fabric density values varied as 110-113 loop $/ \mathrm{cm}^{2}$ for $12 / 1 \mathrm{Ne}, 121-125 \mathrm{loop} / \mathrm{cm}^{2}$ for $16 / 1 \mathrm{Ne}, 124-$ $128 \mathrm{loop} / \mathrm{cm}^{2}$ for $20 / 1 \mathrm{Ne}$ yarn counts. Bursting strength of the fabrics was tested according to ISO 13938-2. Three samples were tested for tensile properties of woven and knitted fabrics. Bending rigidity of the woven fabric samples was also analysed according to ASTM D 1388-96 test method by WIRA bending rigidity tester. Three samples of both of warp and weft direction were tested for each fabric and the average values were determined.

All the tests were carried out on the same testers and test results were analysed statistically by SPSS 16.0 statistical software to determine any significant differences. ANOVA tests were used for two-way analysis of variance for the analysis of the production parameters, multiple-range test LSD method for the comparison of sheath fibre types (Table 2) and t-test for the comparison of yarn counts (Table 3-4) and ANOVA analyses were performed for $\alpha=0.05$ significance level [26]. In the tables, yarn counts of $12 \mathrm{Ne}, 16 / 1 \mathrm{Ne}$ and 20/1 Ne were indicated by 12, 16 and 20 , respectively.

\section{RESULTS AND DISCUSSIONS}

\subsection{Yarn Properties}

In this part, it was given the properties of dual-core spun yarns produced with 50/70 and 70/70 X55+Spandex core filaments and cotton, viscose and cotton/Tencel sheath fibres. The results were coded depending on production parameters and viscose, cotton, cotton/Tencel sheath fibres were shown by $\mathrm{V}, \mathrm{C}$ and $\mathrm{C} / \mathrm{T}$ while $12 \mathrm{Ne}, 16 / 1 \mathrm{Ne}$ and 20/1 Ne yarn counts were displayed by 12, 16 and 20, respectively. The results of ANOVA tests were shown in Tables 2-3.

\section{Yarn unevenness}

Yarn unevenness results are shown in Figure 1. According to $\mathrm{CVm}$ values, dual-core yarns having viscose and cotton/Tencel fibre sheath fibres have significantly lower mass variation values than the yarns having cotton sheath fibres (Table 2). Higher yarn unevenness of cotton sheath fibres corresponds to the results in the core-spun yarns having single elastic core filament [26] and other yarn types. Erdumlu et al. [27] and Kılıç and Okur [28] studied the effect of cotton fibres, viscose rayon fibres and its blends on ring, compact and vortex yarn properties and it was indicated that an increasing ratio of regenerated cellulosic fibre content in the blend decreases unevenness and the lowest $\mathrm{CVm}$ value was found for $33 / 67 \%$ cottonregenerated cellulosic fibre blend [28]. Therefore, findings for the effect of different sheath fibre types on $\mathrm{CVm}$ values of dual-core yarns are in agreement with that of the other yarn types. The reason for $\mathrm{CVm}$ results may be attributed to fibre length and high variation in cotton fibre length compared to viscose and cotton/Tencel fibres. When the yarn becomes finer, unevenness values of the yarns tend to increase as a result of decreasing the number of fibres in yarn structure as reported in other yarn types. Erdumlu et al. [27] reported that mass variation of conventional ring, OE-rotor and vortex increases with finer yarn counts. Örtlek and Ülkü [29] also indicated higher unevenness of finer core-spun vortex yarns than that of the coarser ones. As far as the effect of X55 core filament linear density is concerned, yarn unevenness results change depending on yarn count and sheath fibre types. CVm values mostly decrease with coarser core filament for $12 \mathrm{Ne}$ and $16 \mathrm{Ne}$ yarn counts. However, there is a different trend in $20 \mathrm{Ne}$ dual-core yarns sheathed with viscose and cotton/Tencel fibres and unevenness of the yarns increases with coarser core filament. This trend is consistent with the results of core-spun yarns and unevenness of core-spun yarns having viscose and cotton/Tencel wrapping fibres increases with coarser core filament in $30 \mathrm{Ne}$ and $40 \mathrm{Ne}$ yarn counts [26]. As the core filament is getting coarser, for finer yarn counts in core-spun yarns having single or dual core filaments, core filament can be not covered uniformly with less number of sheath fibres and this case may lead to higher $\mathrm{CVm}$ values. 
Table 2. ANOVA LSD test results for dual-core yarn and fabric properties produced with different sheath fibres and yarn counts

\begin{tabular}{|c|c|c|c|c|c|c|c|}
\hline Property & \multicolumn{2}{|c|}{ Sheath fibres } & \multirow{2}{*}{$\begin{array}{c}\text { Sig. } \\
0.000^{*} \\
0.419\end{array}$} & \multirow{3}{*}{$\begin{array}{c}\text { Property } \\
\text { Woven- } \\
\text { Strength12 }\end{array}$} & \multicolumn{2}{|c|}{ Sheath fibres } & \multirow{2}{*}{$\begin{array}{c}\text { Sig. } \\
0.028^{*} \\
0.000^{*}\end{array}$} \\
\hline \multirow[t]{2}{*}{$\mathrm{CVm} 12$} & Viscose & $\begin{array}{c}\text { Cotton } \\
\text { Cotton/Tencel }\end{array}$ & & & Viscose & $\begin{array}{c}\text { Cotton } \\
\text { Cotton/Tencel }\end{array}$ & \\
\hline & Cotton & Cotton/Tencel & $0.000^{*}$ & & Cotton & Cotton/Tencel & $0.000^{*}$ \\
\hline \multirow{3}{*}{$\mathrm{CVm} 16$} & & Cotton & $0.000^{*}$ & \multirow{3}{*}{$\begin{array}{l}\text { Woven- } \\
\text { Strength } 16\end{array}$} & & Cotton & 0.057 \\
\hline & Viscose & Cotton/Tencel & 0.933 & & Viscose & Cotton/Tencel & $0.000^{*}$ \\
\hline & Cotton & Cotton/Tencel & $0.000^{*}$ & & Cotton & Cotton/Tencel & $0.000^{*}$ \\
\hline \multirow{3}{*}{$\mathrm{CVm} 20$} & & Cotton & $0.000^{*}$ & \multirow{3}{*}{$\begin{array}{l}\text { Woven- } \\
\text { Strength20 }\end{array}$} & & Cotton & 0.095 \\
\hline & Viscose & Cotton/Tencel & $0.001 *$ & & Viscose & Cotton/Tencel & 0.115 \\
\hline & Cotton & Cotton/Tencel & $0.000^{*}$ & & Cotton & Cotton/Tencel & $0.009 *$ \\
\hline \multirow{3}{*}{ Thick12 } & & Cotton & $0.000^{*}$ & \multirow{3}{*}{$\begin{array}{c}\text { Woven- } \\
\text { Elongation } 12\end{array}$} & & Cotton & $0.000^{*}$ \\
\hline & V1scose & Cotton/Tencel & 0.840 & & Viscose & Cotton/Tencel & $0.002 *$ \\
\hline & Cotton & Cotton/Tencel & $0.000^{*}$ & & Cotton & Cotton/Tencel & $0.001^{*}$ \\
\hline \multirow{3}{*}{ Thick16 } & & Cotton & $0.000^{*}$ & \multirow{3}{*}{$\begin{array}{c}\text { Woven- } \\
\text { Elongation } 16\end{array}$} & & Cotton & $0.009^{*}$ \\
\hline & V1scose & Cotton/Tencel & 0.904 & & Viscose & Cotton/Tencel & 0.095 \\
\hline & Cotton & Cotton/Tencel & $0.000^{*}$ & & Cotton & Cotton/Tencel & $0.001^{*}$ \\
\hline \multirow{3}{*}{ Thick20 } & Viscose & Cotton & $0.000^{*}$ & \multirow{3}{*}{$\begin{array}{c}\text { Woven- } \\
\text { Elongation20 }\end{array}$} & Viscose & Cotton & $0.008^{*}$ \\
\hline & V1scose & Cotton/Tencel & 0.658 & & V1scose & Cotton/Tencel & 0.059 \\
\hline & Cotton & Cotton/Tencel & $0.000^{*}$ & & Cotton & Cotton/Tencel & 0.163 \\
\hline \multirow{3}{*}{ Neps12 } & Viscose & Cotton & $0.000^{*}$ & \multirow{3}{*}{$\begin{array}{l}\text { Knitted- } \\
\text { Bursting12 }\end{array}$} & Viscose & Cotton & $0.009^{*}$ \\
\hline & V1scose & Cotton/Tencel & 0.868 & & V 1scose & Cotton/Tencel & $0.002 *$ \\
\hline & Cotton & Cotton/Tencel & $0.000^{*}$ & & Cotton & Cotton/Tencel & 0.160 \\
\hline & Viscose & Cotton & $0.000^{*}$ & & Viscose & Cotton & $0.000^{*}$ \\
\hline Neps16 & V1scose & Cotton/Tencel & 0.729 & $\begin{array}{l}\text { Knitted- } \\
\text { Bursting16 }\end{array}$ & Viscose & Cotton/Tencel & $0.000^{*}$ \\
\hline & Cotton & Cotton/Tencel & $0.000^{*}$ & & Cotton & Cotton/Tencel & $0.000^{*}$ \\
\hline & & Cotton & $0.000^{*}$ & & & Cotton & 0.175 \\
\hline Neps 20 & Viscose & Cotton/Tencel & 0.667 & $\begin{array}{l}\text { Knitted- } \\
\text { Bursting?0 }\end{array}$ & Viscose & Cotton/Tencel & $0.006^{*}$ \\
\hline & Cotton & Cotton/Tencel & $0.000^{*}$ & & Cotton & Cotton/Tencel & $0.001^{*}$ \\
\hline & & Cotton & $0.000^{*}$ & & & & \\
\hline $\mathrm{H} 12$ & Viscose & Cotton/Tencel & 0.487 & & & & \\
\hline & Cotton & Cotton/Tencel & $0.001 *$ & & & & \\
\hline & Viscose & Cotton & $0.001^{*}$ & & & & \\
\hline $\mathrm{H} 16$ & Viscose & Cotton/Tencel & 0.520 & & & & \\
\hline & Cotton & Cotton/Tencel & $0.003^{*}$ & & & & \\
\hline & & Cotton & $0.000^{*}$ & & & & \\
\hline $\mathrm{H} 20$ & V1scose & Cotton/Tencel & 0.073 & & & & \\
\hline & Cotton & Cotton/Tencel & $0.015^{*}$ & & & & \\
\hline & & Cotton & 0.773 & & & & \\
\hline Tenacity 12 & Viscose & Cotton/Tencel & $0.006^{*}$ & & & & \\
\hline & Cotton & Cotton/Tencel & $0.013^{*}$ & & & & \\
\hline & Viscose & Cotton & $0.049^{*}$ & & & & \\
\hline Tenacity 16 & V1scose & Cotton/Tencel & $0.001 *$ & & & & \\
\hline & Cotton & Cotton/Tencel & $0.000^{*}$ & & & & \\
\hline & & Cotton & $0.000^{*}$ & & & & \\
\hline Tenacity 20 & Viscose & Cotton/Tencel & 0.842 & & & & \\
\hline & Cotton & Cotton/Tencel & $0.000^{*}$ & & & & \\
\hline & & Cotton & $0.000^{*}$ & & & & \\
\hline Elogantion 12 & V1scose & Cotton/Tencel & 0.787 & & & & \\
\hline & Cotton & Cotton/Tencel & $0.000^{*}$ & & & & \\
\hline & & Cotton & $0.000^{*}$ & & & & \\
\hline Elogantion 16 & Viscose & Cotton/Tencel & 0.717 & & & & \\
\hline & Cotton & Cotton/Tencel & $0.000^{*}$ & & & & \\
\hline & & Cotton & $0.000^{*}$ & & & & \\
\hline Elogantion 20 & Viscose & Cotton/Tencel & $0.000^{*}$ & & & & \\
\hline & Cotton & Cotton/Tencel & $0.000^{*}$ & & & & \\
\hline
\end{tabular}

*The mean difference is significant at the 0.05 level. 
Table 3. t-test results of dual-core yarns produced with different sheath fibres and yarn counts for yarn properties

\begin{tabular}{cccccccc}
\hline \multirow{2}{*}{ Production parameters } & CVm & $\begin{array}{c}\text { Thick } \\
\text { places }\end{array}$ & Neps & H & Tenacity & Elongation \\
\hline \multirow{2}{*}{ Viscose } & $12 \mathrm{Ne}$ & $0.000^{*}$ & 0.111 & $0.006^{*}$ & $0.000^{*}$ & $0.000^{*}$ & $0.000^{*}$ \\
& $16 \mathrm{Ne}$ & $0.000^{*}$ & $0.001^{*}$ & $0.001^{*}$ & $0.000^{*}$ & $0.000^{*}$ & $0.000^{*}$ \\
& $20 \mathrm{Ne}$ & $0.000^{*}$ & 0.082 & $0.000^{*}$ & $0.000^{*}$ & $0.000^{*}$ & $0.000^{*}$ \\
\hline \multirow{6}{*}{ Cotton } & & & & & & \\
& $12 \mathrm{Ne}$ & $0.000^{*}$ & $0.000^{*}$ & $0.000^{*}$ & $0.000^{*}$ & $0.000^{*}$ & $0.000^{*}$ \\
& $16 \mathrm{Ne}$ & $0.000^{*}$ & $0.000^{*}$ & $0.000^{*}$ & $0.000^{*}$ & $0.000^{*}$ & $0.000^{*}$ \\
\hline & $20 \mathrm{Ne}$ & $0.000^{*}$ & $0.000^{*}$ & $0.000^{*}$ & $0.000^{*}$ & $0.000^{*}$ & $0.000^{*}$ \\
\hline \multirow{2}{*}{ Cotton/Tencel } & & & & & & & \\
& $12 \mathrm{Ne}$ & $0.000^{*}$ & $0.000^{*}$ & $0.000^{*}$ & $0.000^{*}$ & $0.000^{*}$ & $0.000^{*}$ \\
& $16 \mathrm{Ne}$ & $0.000^{*}$ & $0.000^{*}$ & $0.000^{*}$ & $0.000^{*}$ & $0.000^{*}$ & $0.000^{*}$ \\
\hline
\end{tabular}

*The mean difference is significant at the 0.05 level.

Table 4. t-test results of dual-core yarns produced with different sheath fibres and yarn counts for fabric properties

\begin{tabular}{ccccc}
\hline \multicolumn{2}{c}{ Production parameters } & Strength & Elongation & Bursting strength \\
\hline \multirow{3}{*}{ Viscose } & $12 \mathrm{Ne}$ & $0.000^{*}$ & $0.000^{*}$ & $0.000^{*}$ \\
& $16 \mathrm{Ne}$ & $0.000^{*}$ & $0.000^{*}$ & $0.000^{*}$ \\
& $20 \mathrm{Ne}$ & $0.000^{*}$ & $0.000^{*}$ & $0.000^{*}$ \\
& & & $0.000^{*}$ \\
& $12 \mathrm{Ne}$ & $0.000^{*}$ & $0.000^{*}$ & $0.000^{*}$ \\
\hline \multirow{3}{*}{ Cotton } & $16 \mathrm{Ne}$ & $0.000^{*}$ & $0.000^{*}$ & $0.000^{*}$ \\
& $20 \mathrm{Ne}$ & $0.000^{*}$ & & $0.000^{*}$ \\
& & & $0.000^{*}$ & $0.000^{*}$ \\
Cotton/Tencel & $12 \mathrm{Ne}$ & $0.000^{*}$ & $0.000^{*}$ & $0.000^{*}$ \\
\hline
\end{tabular}

*The mean difference is significant at the 0.05 level.

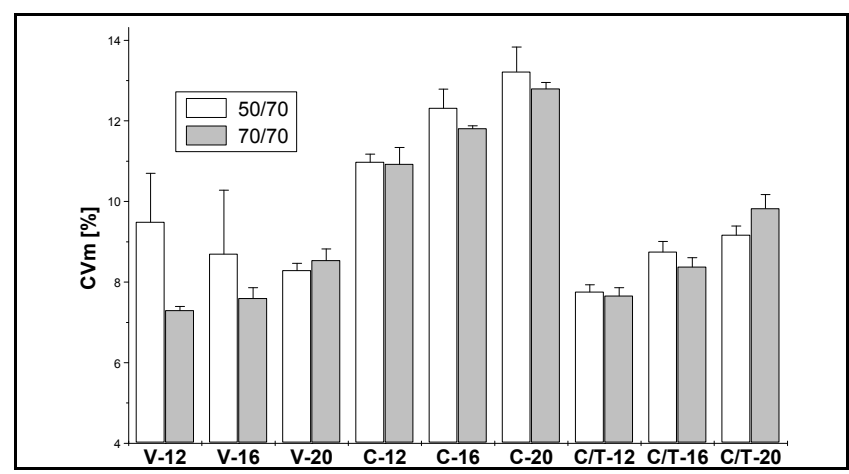

Figure 1. Yarn unevenness results

ANOVA results indicate that the effects of sheath fibre $(p=0.000)$ and yarn count $(p=0.000)$ are statistically significant at $5 \%$ level. However, sheath fibre*yarn count $(\mathrm{p}=0.193)$, core filament linear density $(\mathrm{p}=0.273)$ and its interactive effects with sheath fibre $(\mathrm{p}=0.639)$, yarn count $(\mathrm{p}=0.424)$ and sheath fibre*yarn count $(\mathrm{p}=0.921)$ do not have statistically significant effect on the yarn irregularity values. Therefore, these results suggest that sheath fibre type due to its effect on fibre properties and yarn count related from its effect on number of fibres in yarn structure have a relatively higher significant influence on yarn unevenness in comparison to core filament linear density.

\section{Yarn imperfections}

In the study, it was not determined any thin places for all yarn types. However, thick places and neps values are given in Figures 2-3 and statistical test results are given in Tables 2-3. According to the results, dual-core yarns produced with cotton sheath fibres have significantly higher thick places and neps values than the yarns with viscose and cotton/Tencel wrapping fibres. As in yarn unevenness results, yarn imperfections are getting higher with the finer yarn counts. Regarding the core filament linear density, there is no clear trend in the results of thick places of all dual-core yarns. However, neps values seem to be increased as the core filament becomes coarser. This result is also in harmony with the findings determined for core-spun yarns having single core filament at the yarn centre [26].

When the thick places of dual-core spun yarns are analysed statistically, ANOVA results indicate that effects of sheath fibre $(\mathrm{p}=0.000)$, yarn count $(\mathrm{p}=0.000)$ and sheath fibre*yarn count $(\mathrm{p}=0.000)$ are statistically significant at $5 \%$ level. However, core filament linear density $(\mathrm{p}=0.222)$ and its 
interactive effects with sheath fibre $(p=0.223)$, yarn count $(\mathrm{p}=0.379)$ and sheath fibre*yarn count $(\mathrm{p}=0.310)$ do not have considerably affect on thick places values of the yarns. As to neps faults, similar trend is observed and sheath fibre $(p=0.000)$, yarn count $(p=0.000)$ and sheath fibre*yarn count $(p=0.000)$ have statistically more important influence while the effect of core filament linear density $(p=0.364)$ and its interactive effects with sheath fibre $(\mathrm{p}=0.124)$, yarn count $(p=0.110)$ and sheath fibre* yarn count $(p=0.287)$ are not statistically significant level on the neps values. As in yarn unevenness, the results reveal that sheath fibre type and yarn count are the considerably important production parameters for lower thick places and neps faults and both core filament linear density values lead to similar yarn faults at the same sheath fibres and yarn counts.

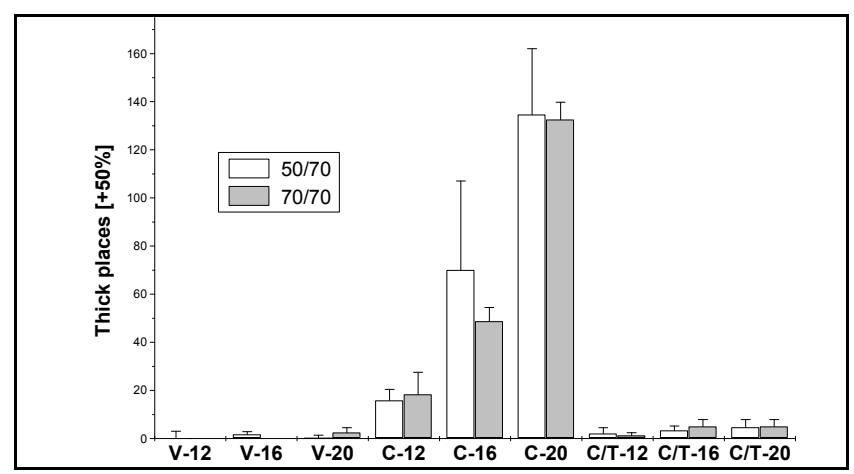

Figure 2. Thick places results

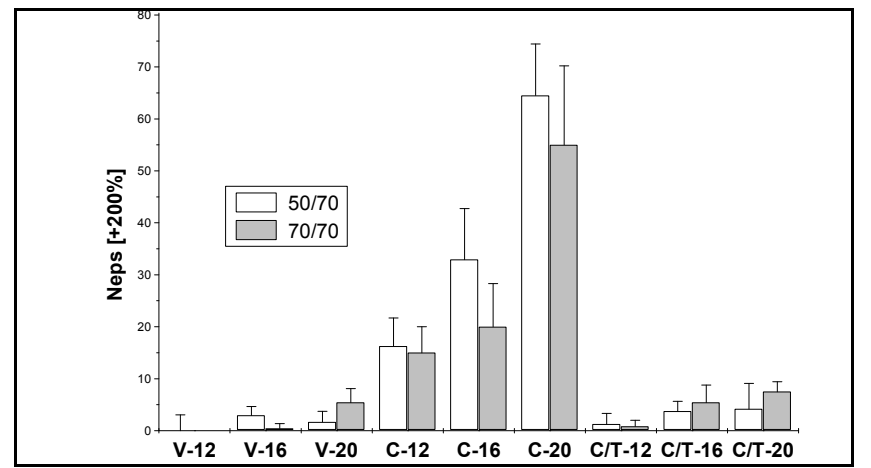

Figure 3. Neps results

\section{Yarn hairiness}

Hairiness properties of dual-core yarns were evaluated by Uster hairiness index $(\mathrm{H})$ and the yarns containing cotton sheath fibres have been found to be more hairy while the yarns having viscose covering fibres have significantly lower hairiness values (Figure 4). In particular, $\mathrm{H}$ values of cotton fibres are significantly different from other sheath fibres while viscose and cotton/Tencel sheath fibres give statistically similar yarn hairiness. Erdumlu et al. [27] also reported for different yarn types like ring, rotor and vortex and longer length of viscose rayon fibre, when compared with cotton, provided fewer protruding fibres and lower $\mathrm{H}$ values. Hence, fibre length of sheath fibres plays an important role in the hairiness values for spun yarns.
Hairiness index of all dual-core yarns decreases with a reduction in the yarn count and less number of fibres in yarn cross-section gives lower hairiness index, as in other yarn types. On the other hand, for the effect of core filament linear density, different trends have been observed depending on the sheath type and yarn count. As the core filament become coarser, hairiness values increase in $16 / 1$ $\mathrm{Ne}$ and 20/1 Ne cotton, and 12/1 $\mathrm{Ne}$ and 16/1 Ne cotton/Tencel sheathed dual-core yarns. For dual-core yarns with cotton/Tencel wrapping fibres, coarser core filament may decrease the yarn hairiness due to lower percentage of cotton sheath fibres. For cotton sheath fibres, in contrast to our expectations, coarser core filament causes higher yarn hairiness in $20 \mathrm{Ne}$ yarn count. In another part of this study, this trend was observed for 30 and $40 \mathrm{Ne}$ cotton sheathed core-spun yarns while $20 \mathrm{Ne}, 30 \mathrm{Ne}$ and $40 \mathrm{Ne}$ viscose and cotton/Tencel wrapped core-spun yarns, and hairiness of core-spun yarns increased with coarser core filament usage [26]. Hence, one may think that yarn hairiness starts to increase beyond the certain yarn count because of the coarser core filament and the limit for yarn count changes depending on sheath fibre type.

When ANOVA results are analysed, it is determined that sheath fibre $(p=0.000)$, yarn count $(p=0.000)$ and yarn count*core filament linear density $(p=0.006)$ have statistically significant effect on $\mathrm{H}$ hairiness values of dualcore yarns. However, core filament linear density $(p=0.447)$ and interactive effects of sheath fibre*yarn count $(\mathrm{p}=0.103)$, sheath fibre*core filament linear density $(p=0.319)$ and sheath fibre*yarn count*core filament linear density $(\mathrm{p}=0.112)$ are found statistically insignificant at 5\% level. Therefore, as in ring spun and other yarn types, staple fibre properties, particularly fibre length, and changes in number of sheath fibres in yarn structure resulted from yarn count and linear density of core filament have a relatively higher significant influence on hairiness of dual-core yarns. Vuruşkan [24] also stated that yarn count is the most effective parameter on yarn hairiness in comparison to yarn twist and elastane draft for core-spun yarns comprising core filament.

The findings regarding the effect of core filament linear density on yarn hairiness is also consistent with the literature $[12-13,29]$ and explained by the more possibility of displacement of the core filament and disrupting the sheath fibres orientation because of higher percentage of elastic core filament in the yarn structure [13]. Another explanation may be insufficiently and improperly coating of coarser core filament due to less number of fibres in finer yarn counts. If the results are concluded in a general expression, core-spun yarns comprising single and dual core filaments with cotton sheath fibres become more hairy with finer yarn counts and coarser core filament linear densities. As to viscose and cotton/Tencel covering fibres, coarser yarn count and core filament linear density lead to higher yarn hairiness. 


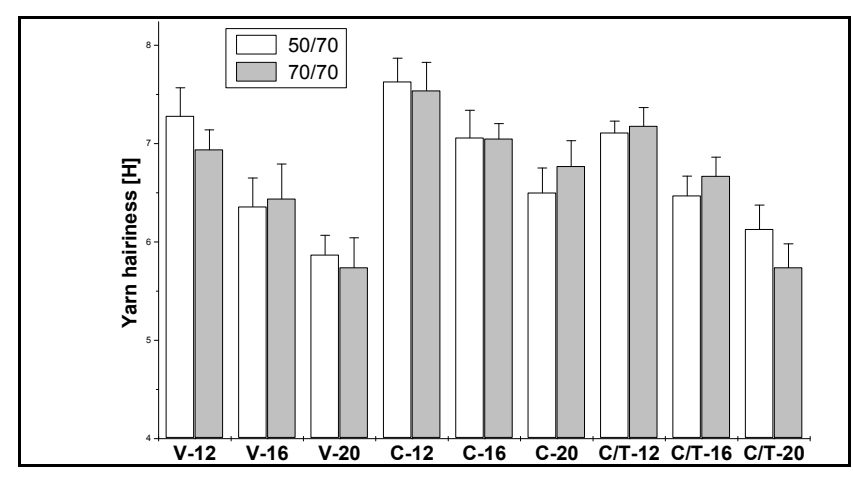

Figure 4. Yarn hairiness results

\section{Yarn tenacity}

Differences in tenacity results are given in Figure 5. When the effect of sheath fibre type on tenacity values of dualcore yarns are examined, the findings are similarly determined in core-spun yarns comprising single elastic component. Dual-core yarns obtained by cotton/Tencel sheath fibres give the highest tenacity values while tenacity of the yarns covered by cotton sheath fibres is the lowest. As the dual-core yarns become finer, as expected, tenacity of the yarns decreases. As far as core filament linear density is concerned, tenacity values of the dual-core yarns reduce with coarser core filament usage except $16 \mathrm{Ne}$ viscose sheathed dual-core yarns. This result is consistent with the findings for core-spun yarns having single elastic core filament [12-13, 26, 30-31], which reported that most of the loading stress is mainly taken up by relatively lesser extensible sheath component in core spun yarns. Therefore, strength of sheath or wrapping fibres mainly determines the overall yarn tenacity of core-spun yarns. As the core filament is getting finer, number of sheath fibres and thus contribution to yarn tenacity increases. This case provides more resistance to applied load and higher tenacity values are achieved [13, 22, 24, 29]. In present study, the findings of lower tenacity values of coarser core filaments confirm these statements and strength of sheath fibres appears to have significant affect on tenacity of dual-core yarns than yarn and core filament linear densities.

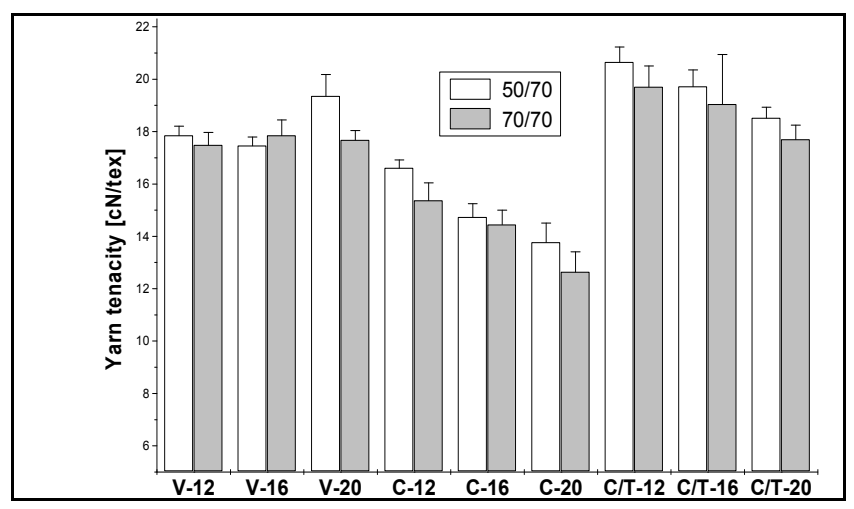

Figure 5. Yarn tenacity results

On the other hand, ANOVA results indicate that the effect of sheath fibre $(p=0.000)$, yarn count $(p=0.000)$ and core filament linear density $(\mathrm{p}=0.000)$ and interactive effects of these parameters $(\mathrm{p}=0.000)$ except sheath fibre*core filament linear density $(p=0.000)$ are found statistically significant level on yarn tenacity values. Therefore, all production parameters of dual-core yarns have a relatively higher significant influence on tenacity of the dual-core yarns.

\section{Yarn breaking elongation}

The results are indicated in Figure 6. For the effect of sheath fibre type, dual-core yarns produced with viscose sheath fibres have the highest values while the yarns having cotton wrapping fibres have the lowest breaking elongation values for all yarn counts and core filament linear densities. Since the elongation of viscose and Tencel fibres are greater than cotton, an increase in yarn elongation is also inevitable [28]. On the other hand, mostly, there are not statistically significant differences in the results of viscose and cotton/Tencel sheath fibres and hence both sheath fibres lead to considerably higher breaking elongation values than the dual-core yarns produced from cotton sheath fibres. Breaking elongation values of the dual-core yarns significantly decrease as the yarn becomes finer for all sheath fibre types. An examination of the effect of core filament linear density on yarn breaking elongation indicates that the increasing ratio of core filament content in the yarn structure with the usage coarser core filament leads to an increase on yarn elongation.

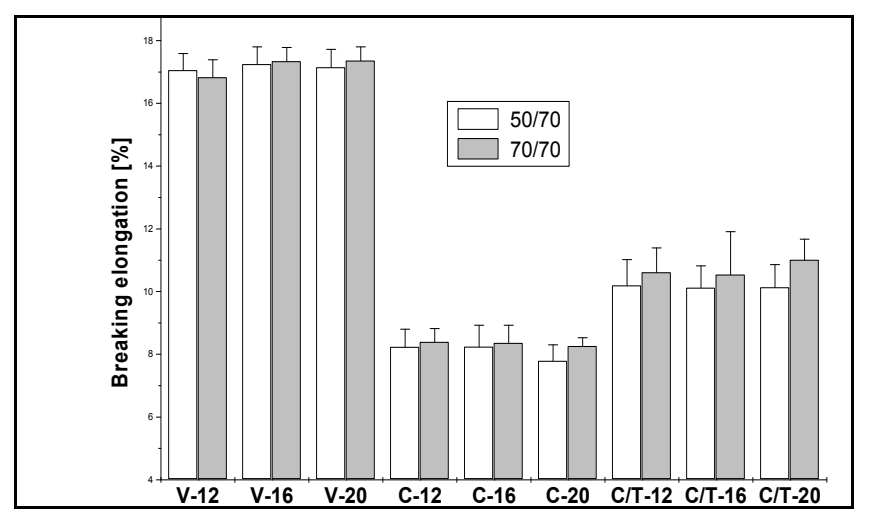

Figure 6. Yarn breaking elongation results

According to ANOVA results, the effects of all parameters and their interactions on breaking elongation are generally statistically significant at 5\% level. Therefore, not only the sheath fibre and yarn count but also core filament linear density is the parameters determining the breaking elongation of dual-core yarns.

\subsection{Fabric Properties}

In this part, it was given some of the woven and knitted fabric properties of 12/1 Ne, 16/1 Ne and 20/1 Ne dual-core spun yarns produced with X55 (50 and 70 denier) and Spandex (70 denier) core filaments and cotton, viscose and cotton/Tencel sheath fibres. ANOVA results were summarized in Table 2 and Table 4. 


\section{Pilling behaviour}

Pilling is a very serious problem for the fabrics that arises after the usage of the fabric. Pilling behaviour of all fabrics was tested and Table 5 displays the pilling rates of the woven fabrics produced from dual-core yarns having different sheath fibres, yarn counts and core filament linear densities. A general assessment shows that the fabrics woven from dual-core yarns comprising viscose and cotton/Tencel sheath fibres have almost similar pilling rates for all yarn counts. However, the fabrics produced from the dual-core yarns with cotton sheath fibres have a bit higher pilling tendency than the other fabrics. This trend may result from higher yarn Uster $\mathrm{H}$ hairiness values of cotton sheathed dual-core yarns. Upon a general evaluation of pilling results of the dual-core yarns indicates that the sheath fibre properties is more effective on yarn hairiness and thus pilling behaviour of the fabrics is affected from sheath fibre characteristics in comparison to the effect of the yarn count and core filament linear density.

\section{Tensile properties of the woven fabrics}

As reported, dual-core yarns were used as weft yarn during the woven fabric production and fabric strength and breaking elongation was tested for only weft direction because of the inadequate fabric sample. When the tensile properties of the fabrics are analysed, different trend is observed depending on yarn count. In the fabrics woven from $12 \mathrm{Ne}$ and $20 \mathrm{Ne}$ dual-core yarns, fabric breaking strength values are higher for the fabrics having cotton/Tencel sheathed fibres while lower for the fabrics having cotton fibres (Figure 7). The possible reason for this result could be the tenacity values of these yarns. Furthermore, in $12 \mathrm{Ne}$ yarn count, finer core filament provides higher fabric strength while an inverse tendency becomes in $16 \mathrm{Ne}$ and $20 \mathrm{Ne}$ yarn counts and lower fabric strength is obtained for all sheath fibre types. According to statistical results, as determined in yarn tensile properties, the effect of sheath fibre $(p=0.000)$, yarn count $(p=0.000)$ and its interactive effects of sheath fibre*yarn count $(p=0.000)$ are found statistically significant level on fabric strength. The effect of core filament linear density is seen to be statistically important depending on sheath fibre type and yarn count and interactive effects of core filament linear density with sheath fibre $(p=0.003)$, yarn count $(p=0.000)$ and sheath fibre*yarn count $(p=0.000)$ are statistically significant level on fabric strength.

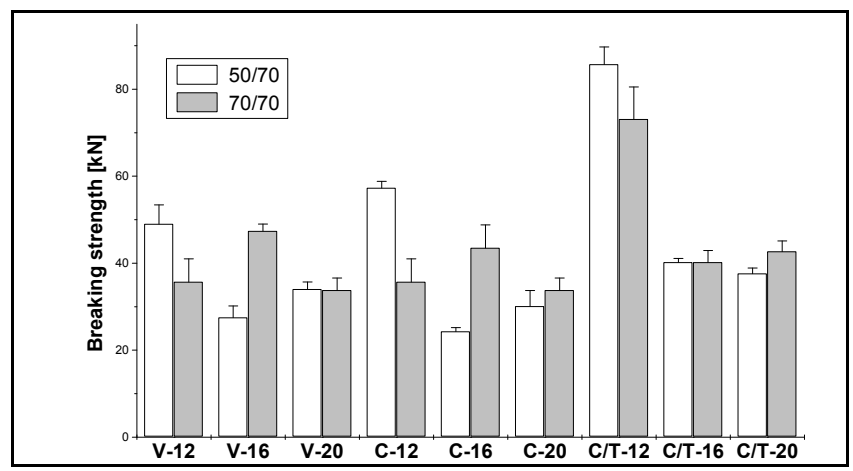

Figure 7. Breaking strength values of woven fabrics

Table 5. Pilling property of the fabrics

\begin{tabular}{llcccccc}
\hline Yarn type & $\begin{array}{c}\mathbf{5 0 0} \\
\text { cycle }\end{array}$ & $\begin{array}{c}\mathbf{1 0 0 0} \\
\text { cycle }\end{array}$ & $\begin{array}{c}\mathbf{2 0 0 0} \\
\text { cycle }\end{array}$ & $\begin{array}{c}\mathbf{3 0 0 0} \\
\text { cycle }\end{array}$ & $\begin{array}{c}\mathbf{5 0 0 0} \\
\text { cycle }\end{array}$ & $\begin{array}{c}\mathbf{7 0 0 0} \\
\text { cycle }\end{array}$ \\
\hline & Viscose-50/70 denier & $4-5$ & $4-5$ & $3-4$ & $3-4$ & $3-4$ & $3-4$ \\
& Viscose-70/70denier & $4-5$ & $4-5$ & $4-5$ & $3-4$ & $3-4$ & $3-4$ \\
$12 \mathrm{Ne}$ & Cotton-50/70 denier & $4-5$ & $3-4$ & $3-4$ & $3-4$ & $3-4$ & $2-3$ \\
& Cotton-70/70 denier & $4-5$ & $3-4$ & $3-4$ & $3-4$ & $3-4$ & $2-3$ \\
& Cotton/Tencel-50/70 denier & $4-5$ & $4-5$ & $4-5$ & $3-4$ & $3-4$ & $3-4$ \\
Cotton/Tencel-70/70 denier & $4-5$ & $4-5$ & $4-5$ & $3-4$ & $3-4$ & $3-4$ \\
\hline & & & & & & \\
$16 \mathrm{Ne}$ & $4-5$ & $4-5$ & $4-5$ & $4-5$ & $3-4$ & $3-4$ \\
& Viscose-50/70 denier & $4-5$ & $4-5$ & $4-5$ & $4-5$ & $3-4$ & $3-4$ \\
& Viscose-70/70denier & $4-5$ & $3-4$ & $3-4$ & $3-4$ & $3-4$ & $2-3$ \\
Cotton-50/70 denier & $4-5$ & $3-4$ & $3-4$ & $3-4$ & $3-4$ & $3-4$ \\
& Cotton-70/70 denier & $4-5$ & $4-5$ & $4-5$ & $3-4$ & $3-4$ & $3-4$ \\
Cotton/Tencel-50/70 denier & $4-5$ & $4-5$ & $4-5$ & $3-4$ & $3-4$ & $3-4$ \\
\hline Cotton/Tencel-70/70 denier & & & & & & \\
& & $4-5$ & $4-5$ & $4-5$ & $4-5$ & $3-4$ & $3-4$ \\
& Viscose-50/70 denier & $4-5$ & $4-5$ & $4-5$ & $4-5$ & $3-4$ & $2-3$ \\
& Viscose-70/70denier & $4-5$ & $4-5$ & $4-5$ & $4-5$ & $3-4$ & $3-4$ \\
Cotton-50/70 denier & $4-5$ & $4-5$ & $4-5$ & $4-5$ & $3-4$ & $3-4$ \\
Cotton-70/70 denier & $4-5$ & $4-5$ & $4-5$ & $3-4$ & $3-4$ & $3-4$ \\
& Cotton/Tencel-50/70 denier & $4-5$ & $4-5$ & $4-5$ & $3-4$ & $3-4$ & $3-4$ \\
\hline
\end{tabular}


When the breaking elongation results of the woven fabrics are studied, it is seen that the dual-core yarns having viscose sheath fibres give significantly higher fabric breaking elongation values than the other sheath fibres as in yarn breaking elongation (Figure 8). On the other hand, there are no clear trend regarding the effect of core filament linear density on fabric breaking elongation and elongation values of the fabrics change depending on yarn counts and sheath fibre types. According to statistical results, as determined in yarn tensile properties, the effect of sheath fibre $(p=0.000)$, yarn count $(p=0.019)$ and core filament linear density $(p=0.000)$ and interactive effects of yarn count*core filament linear density $(p=0.000)$ and sheath fibre*yarn count*core filament linear density $(p=0.000)$ except sheath fibre*core filament linear density $(p=0.225)$ are found statistically significant level on fabric breaking elongation values. Therefore, yarn count, type of sheath fibre and core filament linear density influences the tensile properties of the woven fabrics significantly.

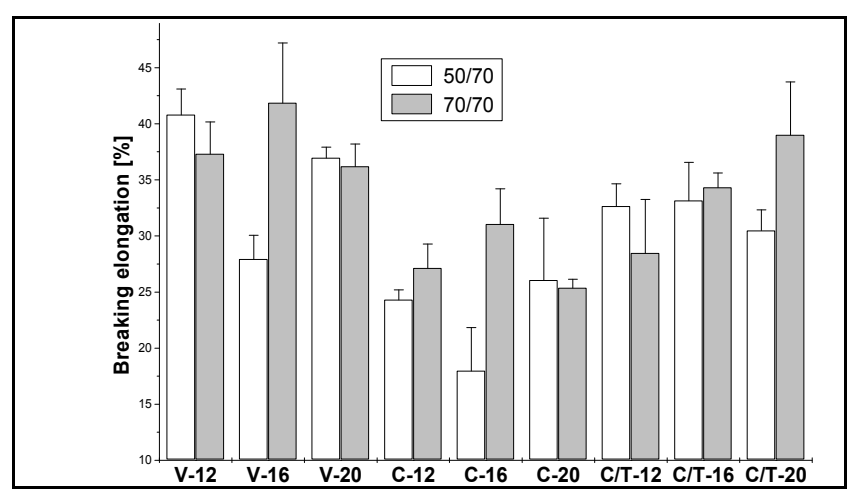

Figure 8. Breaking elongation values of woven fabrics

\section{Bursting strength}

Bursting strength is the ability of the fabric to resist rupture by pressure and depends on the tensile strength and extensibility of the material. In this study, the bursting strength of the fabrics knitted from the dual-core yarns produced from different sheath fibres and core filament linear density were measured for three different yarn counts and comparisons were realized. According to the results, bursting strength results of plain knitted fabrics in Figure 9 change depending on sheath fibre and core filament linear densities. Upon the general evaluation of the sheath fibres, dual-core yarns having cotton and cotton/Tencel sheath fibres give higher bursting strength values than that of the viscose sheath fibres due to strength characteristics of the sheath fibres. This result is agreed with findings of [27] in which investigated the yarn and fabric properties of different yarn types produced from various fibre types. On the other hand, ANOVA results indicate that the effect of sheath fibre $(p=0.000)$, yarn count $(p=0.000)$ and interactive effects of these parameters $(\mathrm{p}=0.000)$, sheath fibre*core filament linear density $(\mathrm{p}=0.027)$, sheath fibre*yarn count*core filament linear density $(p=0.000)$ are found statistically significant level. However, core filament linear density $(p=0.204)$ and sheath fibre*core filament linear density $(p=0.250)$ do not have statistically significant effect on fabric bursting strength. The usage of coarser core filament provides higher bursting strength values in $12 \mathrm{Ne}$ and $16 \mathrm{Ne}$ yarn counts for the fabrics having viscose and cotton sheath fibres while this case is observed in $20 \mathrm{Ne}$ yarn count for cotton/Tencel sheath fibre.

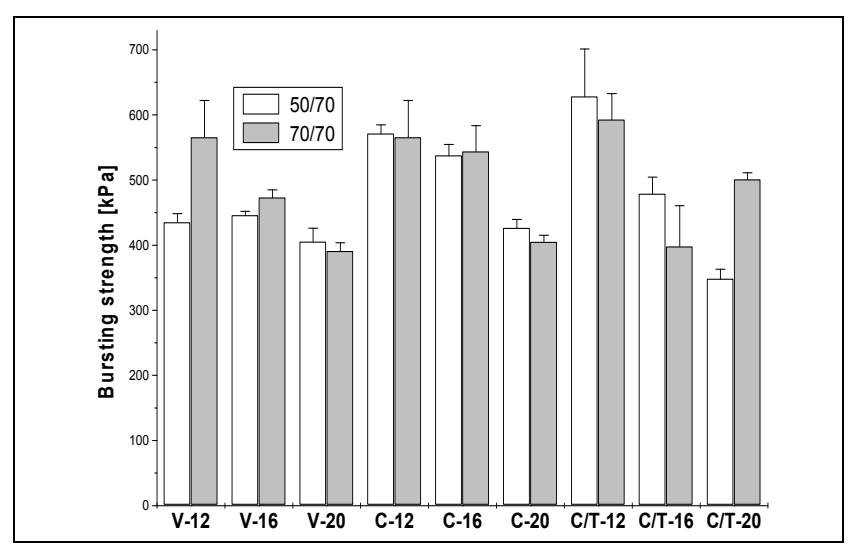

Figure 9. Bursting strength values of knitted fabrics

\section{Bending rigidity}

Bending resistance is the resistance of a certain size of textile sample to bend under its own weight and one of the parameter representing the fabric comfort. In the study, bending rigidity of the fabrics was tested for warp and weft direction and calculated for the samples and the results were given Figure 10. As far as the effect of sheath fibre type is concerned, the fabrics woven from dual-core yarns having cotton/Tencel sheath fibres have mostly higher rigidity values compared with that of the cotton and viscose sheathed fibres. However, the effect of the sheath fibre type and also yarn count are not statistically significant on bending rigidity of the fabrics. On the other hand, an investigation of the effect of the core filament linear density shows that bending rigidity of the fabrics change depending on yarn count and sheath fibre type. For viscose and cotton sheath fibres, coarser core filament leads to higher bending rigidity up to certain yarn counts and then rigidity decreases with core filament linear density. However, for cotton/Tencel sheath fibres, coarser core filament leads to lower fabric bending rigidity values.

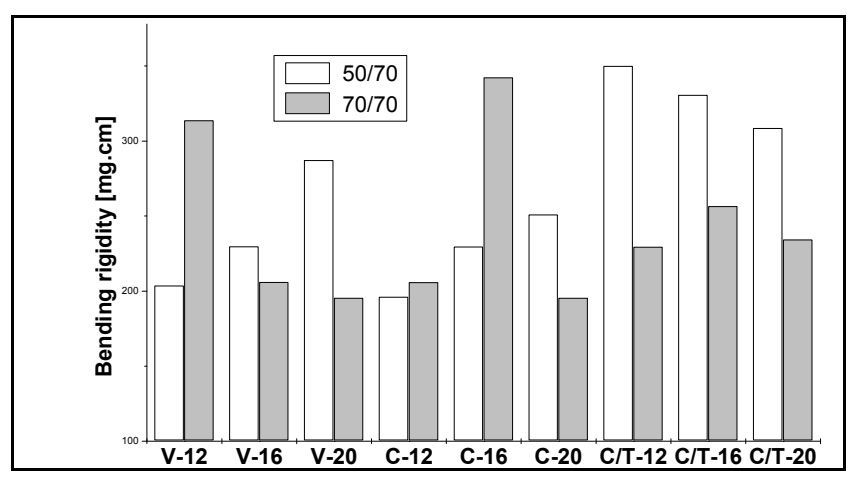

Figure 10. Bending rigidity results of woven fabrics 


\section{CONCLUSIONS}

This study investigated dual-core yarn and fabric properties obtained by different sheath fibre types, yarn counts and core filament linear densities. The outstanding properties of dual-core yarns observed within the scope of this study can be summarized as follows.

- Regarding the effect of sheath fibre type, viscose and cotton/Tencel fibre sheath fibres have significantly lower yarn unevenness, imperfections and hairiness values and pilling behaviour resulted from fibre properties, particularly, fibre length, number of short fibres and low variation in fibre length. On the other hand, yarn and fabric tenacity values of dual-core yarns obtained by cotton/Tencel sheath fibres is better than the other yarns due to positive contribution of sheath fibre strength to the yarn tenacity while viscose sheath fibres give higher yarn and fabric elongation values because of the elongation of viscose fibre. Although its effect is considered insignificant, cotton/Tencel sheath fibres have mostly higher fabric bending rigidity values compared with that of the cotton and viscose sheath fibres.

- When the dual-core yarns become finer, yarn unevenness and imperfections increase while hairiness and tensile properties decrease as a result of decreasing number of sheath fibres in yarn structure.

- On the other hand, effect of core filament linear density on dual-core yarn and fabric properties changes depending on yarn count and sheath fibre types as determined in core-spun yarns having single elastic core filament. In a general expression, the results display an increasing or decreasing trend to a certain yarn count while an opposite trend occurs beyond this yarn count for each sheath fibre type, particularly cotton and other sheath fibre types. This case is probably due to improperly coating of core filament, more possibility of displacement of the core filament and disrupting the sheath fibres orientation resulted from changes in number of fibres and fibre properties related from sheath fibre characteristics and yarn counts. Additionally, tenacity of dual-core yarns increases with finer core filaments while higher breaking elongation is obtained with coarser ones in dual-core yarns.

- Statistical results also indicates the significant effect of production parameters of the sheath fibre type and yarn count on yarn unevenness, thick places, neps, yarn hairiness and fabric bursting strength. On the other hand, all production parameters of dual-core yarns have a relatively higher significant influence on tensile properties of the dual-core yarns and hence woven fabrics.

At the end of this study, some findings related with the dual-core yarns with limited number of findings are presented to the literature and also obtained some results about the effect of various process parameters on dual-core yarn and some of the fabric properties.

\section{ACKNOWLEDGEMENTS}

The authors also wish to express their gratitude to MinaTeks Tekstil San. Tic. A.Ş. (Kahramanmaraş/Turkey) for the sample preparation and ADIM Tekstil San. Tic. A.Ş. (Isparta/Turkey), GÖKHAN Tekstil San. Tic. A.Ş. (Denizli/Turkey) and Comfytex (Kayseri/Turkey) for the sample testing.

\section{REFERENCES}

1. Hua T, Wong NS, Tang WM. 2018. Study on properties of elastic core-spun yarns containing a mix of Spandex and PET/PTT bicomponent filament as core Textile Research Journal 88(9), 10651076.

2. Kılıç G. 2017. Improving quality in core-spun yarn production. $\mathrm{PhD}$ thesis, Erciyes Üniversity, Natural and Applied Sciences, Kayseri, Turkey.

3. El-Tantawy S, Sabry M, Bakry M. 2007. The effect of different weft yarn production technique on the pilling property of jeans fabrics International Design Journal 7(3), 161-169.

4. Ertaş OG, Ünal BZ, Celik N. 2016. Analyzing the effect of the elastane-containing dual-core weft yarn density on the denim fabric performance properties The Journal of The Textile Institute 107(1), 116-126.

5. Bizjak M, Kadoğlu H, Kostajnšek K, Çelik P, Bayraktar GB, Duran D, Dimitrovski K. 2017. Properties of elastic fabrics with treated and untreated $\mathrm{Co} / \mathrm{PBT}$ yarns in weft direction IOP Conference Series: Materials Science and Engineering 254(9), 092001.

6. Kaynak HK. 2017. Optimization of stretch and recovery properties of woven stretch fabrics Textile Research Journal 87(5), 582-592.

7. Broega AC, Rocha AM, Souto AP, Ferreira F, Oliveira L. 2016. Development and characterization of cotton elastic yarns to improve

wear comfort of bi-elastic thin fabrics. $16^{\text {th }}$ Autex World Textile Conference 2016 June 8-10, Ljubljana, Slovenia.

8. Kadoğlu H, Dimitrovski K, Marmaralı A, Çelik P, Bayraktar G, Bedez Üte T, Ertekin G, Demšar A, Kostanjek K. 2016. Investigation of the characteristics of elasticised woven fabric by using PBT filament yarns Autex Research Journal 16(2), 109-117.

9. Maqsood M, Tanveer H, Mumtaz HM, NawabY. 2016. Modeling the effect of elastane linear density, fabric thread density, and weave float on the stretch, recovery, and compression properties of bi-stretch woven fabrics for compression garments The Journal of The Textile Institute 107(3), 307-315.

10. Akankwasa NT, Jun W, Yuze Z, Mushtaq M. 2014. Properties of cotton/T-400 and 100\% cotton plain knitted fabric made from ring spun yarn Materialwissenschaft und Werkstofftechnik 45(11), 10391044 .

11. Akankwasa NT, Wang J, Zhang Y. 2015. Study of optimum spinning parameters for production of T-400/cotton core spun yarn by ring spinning The Journal of The Textile Institute 107(4), 504511.

12. Qadir MB, Hussain T, Malik M, Fahemm A, Jeong SH. 2014. Effect of elastane linear density and draft ratio on the physical and mechanical properties of core-spun cotton yarns Journal of Textile Institute 105(7), 753-759. 
13. Das A, Chakraborty R. 2013. Studies on elastane-cotton core-spun stretch yarns and fabrics: Part I-Yarn characteristics Indian Journal of Fibre\&Textile Research 38, 237-243.

14. Helali H, Babay AD, Msahli S. 2012. Influence of dorlastan draft and yarn count on the elastic recovery of the dorlastan core spun yarns Following Cyclic Test 103(4), 378-374.

15. Mourad MM, Elshakankery MH, Almetwally AA. 2012. Physical and stretch properties of woven cotton fabrics containing different rates of Spandex Journal of American Science 8(4), 567-572.

16. Adeli B, Akbar A, Shanbeh GM. 2011. Structural evaluation of elastic core-spun yarns and fabrics under tensile fatigue loading Textile Research Journal 81(2), 137-147.

17. Baghaei B, Shanbeh M, Ghareaghaji AA. 2010. Effect of tensile fatigue cyclic loads on bagging deformation of elastic vowen fabrics Indian Journal of Fibre\&Textile Research 35, 298-302.

18. Çelik P, Bedez Üte T, Özden D, Çömlekçi H, Akkale EC. 2009. Öz/manto oranı ve büküm sayısının filament özlü ipliklerin iplik özelliklerine etkisi Tekstil Teknolojileri Elektronik Dergisi 3(2), 29 37.

19. Herath CN, Kang BC 2008. Dimensional stability of core spun cotton/Spandex single jersey fabrics under relaxation Textile Research Journal 78(3), 209-216.

20. Özdil N. 2008. Stretch and bagging properties of denim fabrics containing different rates of elastane Fibres \& Textiles in Eastern Europe 16(1), 66.

21. El-Ghezal S, Babay A, Dhouib S, Cheikhrouhou M. 2009. Study of the impact of elastane's ratio and finishing process on the mechanical properties of stretch denim The Journal of The Textile Institute 100(3), 245-253.

22. Dhuib AB, El-Ghezal S, Cheikhrouhou M. 2006. A study of the impact of elastane ratio on mechanical properties of cotton wrapped elastane-core spun yarns The Journal of the Textile Institute 97(2), 167-172.
23. Demirbaș S. 2005. Farklı elastomerik elyaf çeșitlerinin fiziksel özelliklerinin karşılaştırılması. Yüksek Lisans Tezi, Süleyman Demirel Üniversitesi, Fen Bilimleri Enstitüsü, Isparta.

24. Vuruşkan D. 2010. The Optimization Of Production Variables Of Modified Ring Spinning Machine For Producing Yarn With Elastane And Effect Of Variables On Yarn Quality. PhD thesis, Çukurova University, Natural and Applied Sciences, Adana, Turkey.

25. Hu J, Lu J, Zhu Y. 2008. New developments in elastic fibers Polymer Reviews 48(2), 275-301.

26. Celikkan SH. 2018. An Investigation Of The Yarn And Fabric Properties Of Core And Dual Core Elastane Spun Yarns. MSc. Thesis, Süleyman Demirel University, Natural and Applied Sciences, Isparta, Turkey.

27. Erdumlu N, Ozipek B, Oztuna AS, Cetinkaya S. 2009. Investigation of vortex spun yarn properties in comparison with conventional ring and open-end rotor spun yarns Textile Research Journal 79(7), 585595.

28. Kilic M, Okur A. 2011. The properties of cotton-Tencel and cottonPromodal blended yarns spun in different spinning systems Textile Research Journal 81(2), 156-172.

29. Örtlek HG, Ülkü Ș. 2007. Effects of Spandex and yarn counts on the properties of elastic core-spun yarns produced on Murata vortex spinner Textile Research Journal 77(6), 432-436.

30. Kim HJ, Yang HW, Zhu CH, Huh Y. 2009. Influence of the coresheath weight ratio and twist on the tensile strength of the ring core yarns with high tenacity filaments Fibers And Polymers 10(4), 546550 .

31. Babaarslan O. 2001. Method of producing a polyester/viscose corespun yarn containing Spandex using a modified ring spinning frame Textile Research Journal 71(4), 367-371. 